\title{
SNOW STRATIGRAPHY AND WATER EQUIVALENCE MEASURED WITH AN ACTIVE MIGROWAVE SYSTEM
}

\author{
By D. A. Ellerbruch \\ (Electromagnetic Fields Division, National Bureau of Standards, U.S. Department of \\ Commerce, Boulder, Colorado 80302, U.S.A.) \\ and $\mathrm{H}$. S. Boyne \\ (Department of Earth Resources, Colorado State University, Fort Collins, Colorado 80523, \\ U.S.A.)
}

\begin{abstract}
This paper reports on research on the relationship between the electromagnetic scattering properties and physical properties of snow-pack. An FM-CW active microwave radar system operating in the frequency range $8-12 \mathrm{GHz}$ is used to scatter electromagnetic radiation from surface and subsurface stratigraphic layers in the snow-pack. The amplitude of the scattered radiation as a function of depth in the snow-pack can be correlated with such physical characteristics as density, hardness, stratigraphy, and moisture content. A direct determination of snow-pack water equivalence can be made from these observations.

RÉsumé. Stratigraphie de la neige et équivalent en eau mesurés avec un système actif à micro-onde. Cet article rapporte une recherche sur la relation entre les propriétés de dispersion électromagnétique et les propriétés physiques du manteau neigeux. Un système radar à micro-ondes actives FM-CW dans la gamme de fréquence 8-12 GHz est utilisé pour disséminer une radiation électromagnétique à la surface et aux niveaux stratigraphiques inférieurs dans le manteau neigeux. L'amplitude de cette radiation dispersée en fonction de la profondeur de la neige peut être relié avec des caractéristiques physiques tels que la densité, la dureté, la stratigraphie et la teneur en eau liquide. Une détermination directe de l'équivalent en eau du manteau neigeux peut être tirée de ces observations.

Zusammenfassung. Stratigraphie und Wasserwert des Schnees, gemessen mit einem aktiven Mikrowellensystem. Die Arbeit berichtet von Untersuchungen über die Beziehung zwischen der Streuung elektromagnetischer Wellen in einer Schneedecke und deren physikalischen Eigenschaften. Zur Streuung elektromagnetischer Strahlung an oberflächlichen und tiefer gelegenen Schichten einer Schneedecke wurde ein aktives FM-CWMikrowellen-Radarsystem mit einem Frequenzbereich von 8 bis $12 \mathrm{GHz}$ benutzt. Die Amplitude der gestreuten Strahlung als Funktion der Tiefe in der Schneedecke kann mit physikalischen Parametern wie Dichte, Härte, Schichtung und Feuchtegehalt korreliert werden. Aus diesen Beobachtungen lässt sich der Wasserwert der Schneedecke direkt bestimmen.
\end{abstract}

\section{INTRODUGTION}

The use of electromagnetic sensing with an active microwave system to determine the physical properties of snow-pack has been the subject of both theoretical and experimental investigation for several years (Cumming, 1952; Vickers and Rose, [1973]; Linlor and Smith, 1974; Linlor and others, 1974; Linlor and Jiracek, 1975; Ellerbruch and others, 1977). The various methods employed involve the measurement of the absorption and reflection of electromagnetic waves incident on the snow to determine the complex dielectric properties of the snow-pack. The complex dielectric properties such as dielectric constant, attenuation, and propagation through the snow-pack medium are then interpreted in terms of the physical properties such as density, stratigraphy, water equivalence, and liquid-water content.

While the main advantage of electromagnetic sensing is that the method does not disturb the snow-pack being investigated, the complex interrelationship among the various physical parameters and their effect on the dielectric properties of the medium has made the interpretation of the results somewhat ambiguous (Evans, I965; Ambach and Denoth, 1972; Ellerbruch and others, 1977).

The present paper reports on the use of an active microwave system to determine the water equivalence and stratigraphic layering of snow-pack. Indications of substantial nearsurface activity and the possibility of identifying a characteristically weak layer, called the depth-hoar layer, in the snow-pack are also reported. 


\section{EleGtromagnetic SYSTEMS}

A portable (toboggan mounted) radar system, typically called an FM-CW system, was developed to measure and record profiles of snow-packs down to ground level and to monitor changes in snow stratigraphy as a function of time of day. Details of the system operation are reported elsewhere (Ellerbruch and Belsher, 1978). The system was continuously swept in frequency over the bandwidth 8-12 GHz. Snow depths up to $4 \mathrm{~m}$ have been measured with it.

An Automatic Network Analyzer (ANA) system was also used to measure the complex electromagnetic scattering properties of snow at discrete frequencies over the range $500 \mathrm{MHz}-$ $18 \mathrm{GHz}$. The scattering properties are a function of the snow stratigraphy. These data were collected in the frequency domain and computer processed on site with a Fast Fourier Transform (FFT) algorithm into the time domain. The final output is a synthetic Time Domain Reflection (TDR) profile of the snow.

Two antennas were used in all experiments, one for transmitting the incident signal into the snow and the other to receive the reflected signal. The antennas were either mounted side-by-side above the snow surface, or buried below ground level. All of the results reported were obtained with the antennas at near-normal incidence with respect to the snow surface.

\section{Physical analysis}

The physical characterization of the snow-pack involved the analysis of a snow-pit to obtain density and temperature profiles and stratigraphy. A resistance profile using a ram penetrometer was also measured to determine the hardness of the snow-pack. These data were converted to a snow profile using symbols that are internationally understood and accepted ([International Hydrological Decade], r970). In all cases the snow-pack was left in its natural state until the electromagnetic measurements were completed. The physical analysis was then determined.

\section{EXPERIMENTAL RESULTS}

The data given in Figures $1-3$ are typical of those collected during the $1976-77$ snow season. Three field trips were made to an area near Pass Lake on Loveland Pass, Colorado. The total

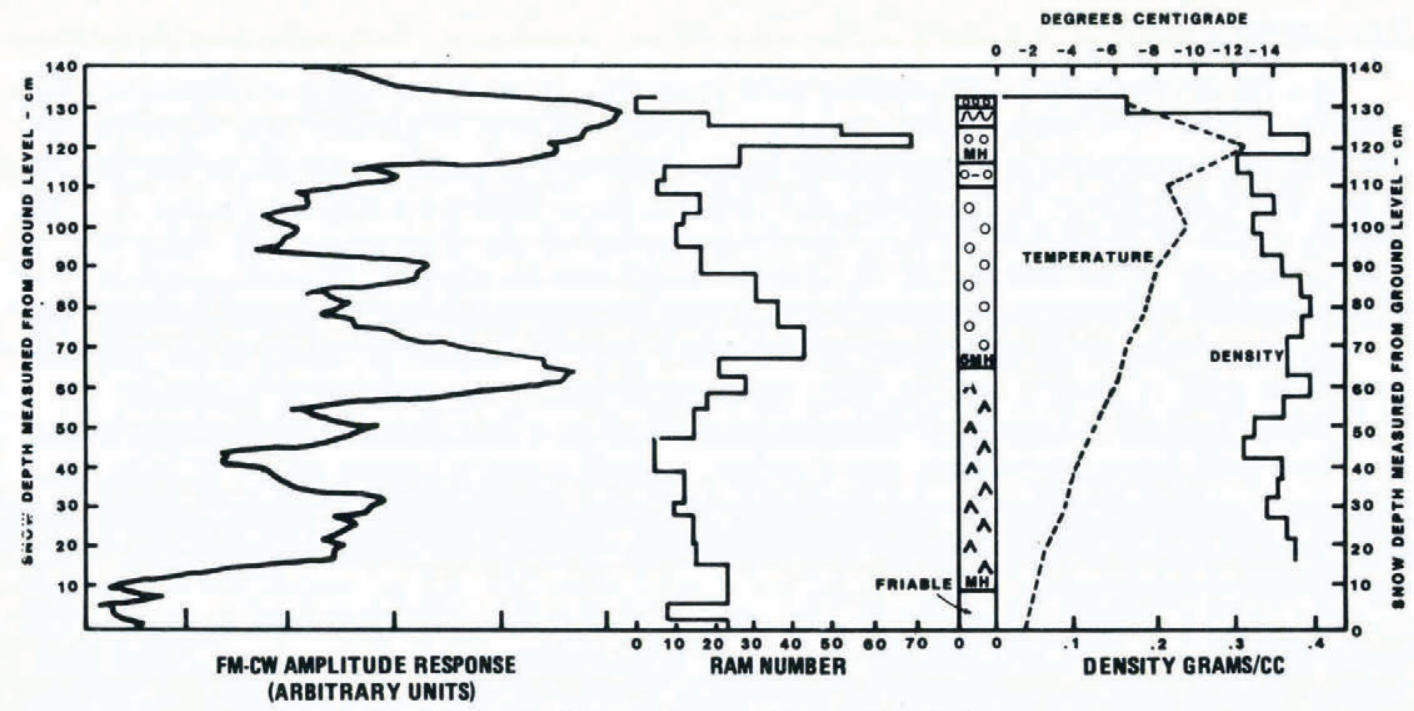

Fig. I. Profile data for a test site near Pass Lake. 
snow depth at the Pass Lake area built up from $110 \mathrm{~cm}$ for the initial experiments in January to $170 \mathrm{~cm}$ for the final experiments in March.

A complete sample of data for one of the Pass Lake Experiments is given in Figure I. An electromagnetic profile for the test point was measured and recorded with the FM-CW microwave system. The data shown on the left are the actual output from that system

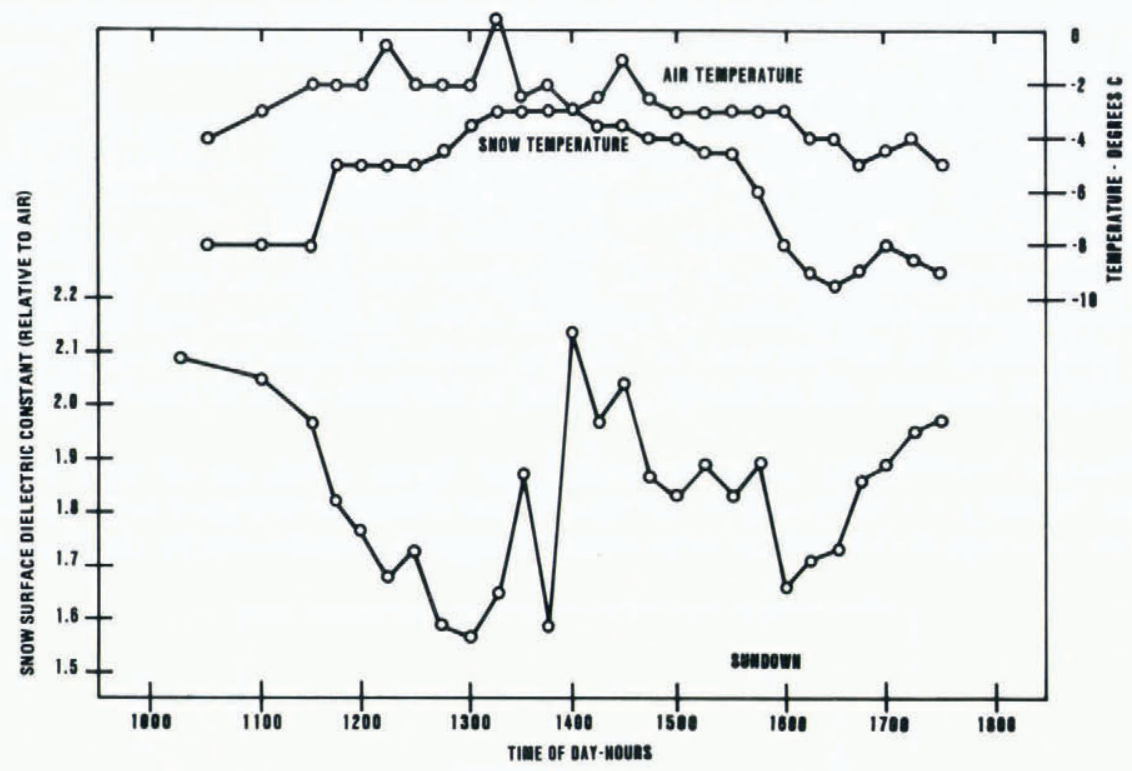

Fig. 2. Surface dielectric-constant and temperature data near Pass Lake.

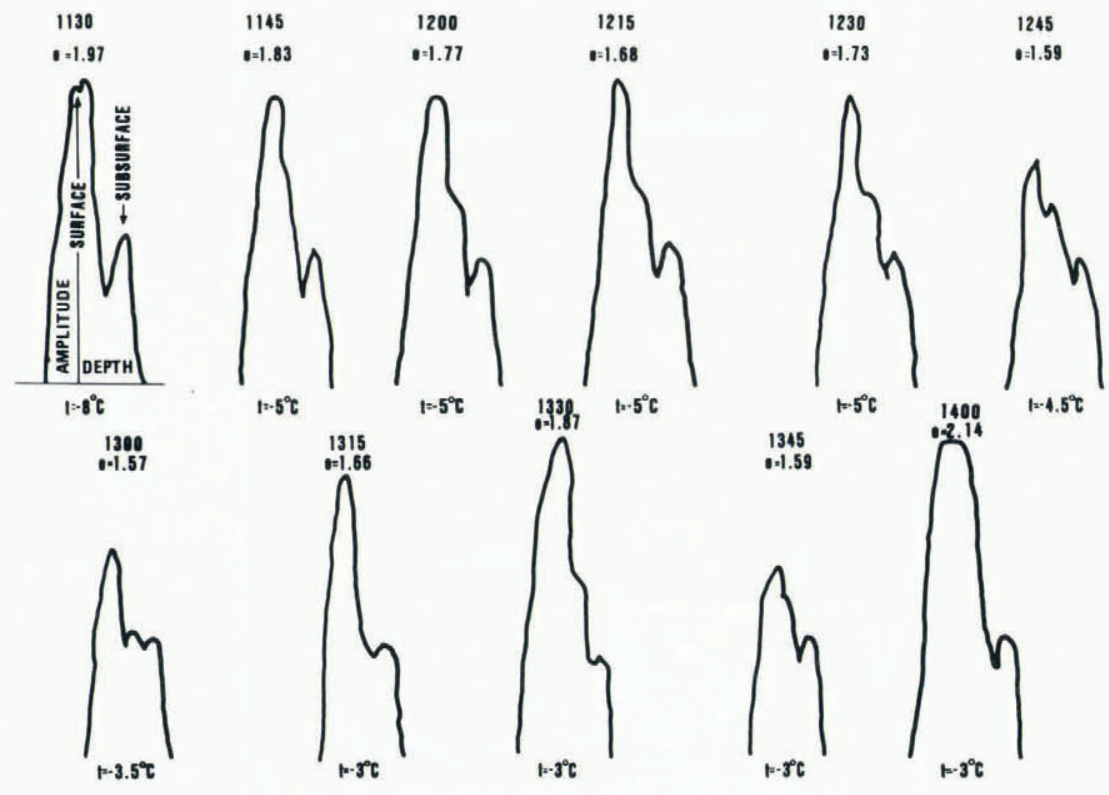

ACTIWITY WITHIM TME UPPEA 15 Ge OF SMOW AS ITS TEMPEAATUAE IMCREASED

Fig. 3. Composite of surface return signals near Pass Lake. 
recorded on site at that time. Next, a resistance profile was measured at the same test point. Then, a pit was dug to obtain the visual characterization of stratigraphy, the temperature profile, and the density profile. All of the data are plotted with respect to a common depth scale measured from the ground in Figure $\mathrm{I}$.

An experiment was designed to monitor a point on the snow surface with the FM-CW system throughout the day to measure the changes at the surface and within the snow-pack as the ambient conditions changed. The surface results obtained from this experiment are given in Figure 2. The snow temperature was obtained with a thermometer that was placed approximately $2 \mathrm{~cm}$ beneath the top of the snow-pack.

As shown in Figure 2, the surface dielectric constant decreased during the time ro.0o $\mathrm{h}$ until $13.00 \mathrm{~h}$. There was no surface melt at that time. It is not yet understood what caused the surface dielectric constant to decrease during that time span; however, it was noted during this experiment that the density of the surface layer of snow also varied as the day progressed. Between the hours 13.00 and 16.00 there was some surface melt causing the surface dielectric constant to increase as expected. After $\mathrm{r} 6.00 \mathrm{~h}$ there was no surface melt; however, after falling to the expected low value at sundown ( $16.00 \mathrm{~h})$, the surface dielectric constant began to increase and essentially returned to the same value as recorded in the early morning.

Considerable activity was underway within the upper $10-20 \mathrm{~cm}$ of snow as the day progressed. Figure 3 is a composite of the near-surface reflection recorded between the hours I I.30-14.00. At I I.30 h two surfaces were clearly measured as evidenced by the large response

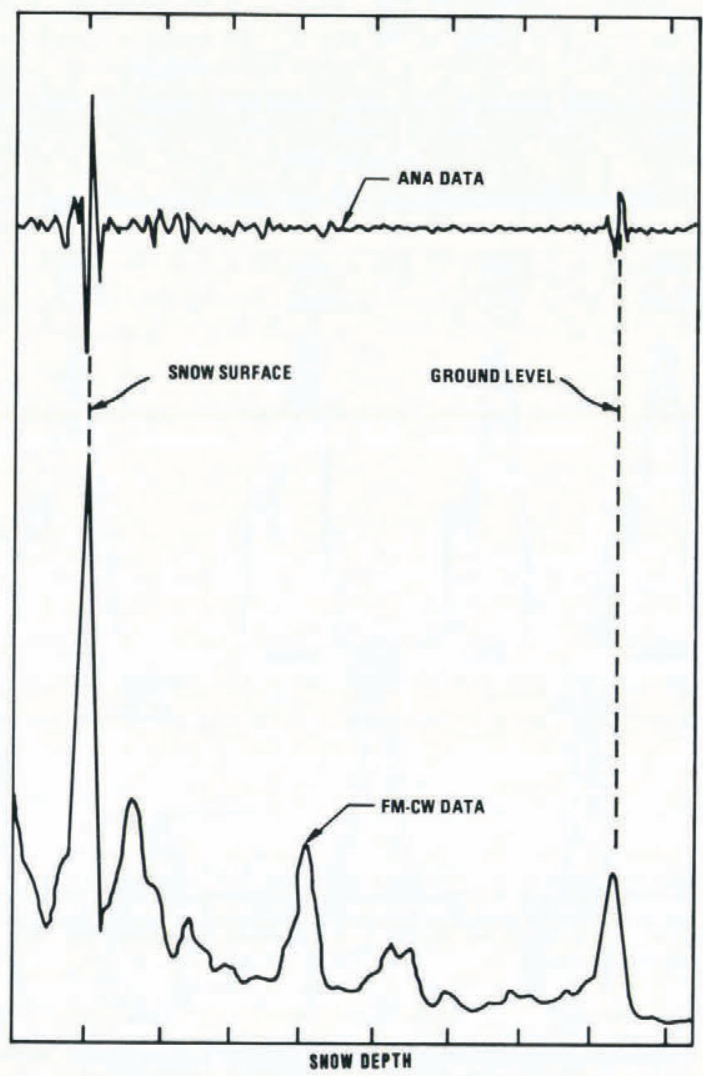

Fig. 4. FM-CW and time-domain data for the snow-pack near Arlington, Wyoming. 
(air-snow interface, $\epsilon=\mathrm{I} .97$ ) and a smaller response which corresponds to an interface $10 \mathrm{~cm}$ within the snow-pack. The smaller response is caused by a hard layer of snow that was found ro $\mathrm{cm}$ below the surface at that point. As time progressed up to $13.00 \mathrm{~h}$, it can be seen that the surface and the subsurface structure within the upper layer changed considerably, even though there was no surface melting. At $13.15 \mathrm{~h}$ and $\mathrm{I} 3.30 \mathrm{~h}$, as shown in Figure 2, some surface melt occurred, as evidenced by the increased air temperature, and the increased surface dielectric constant. At $\mathrm{I} 3.45 \mathrm{~h}$ the temperature decreased and the surface froze, resulting in the multi-layered response shown for that time in Figure 3. Beyond that time, as Figure 2 shows, there was considerable surface melt until sundown.

Figure 4 is a comparison of the microwave responses obtained in Wyoming with the FM-CW system and with the ANA. The ANA data have been transformed into the time domain using a discrete Fast Fourier Transform. The snow surface, the ground, and some of the strata have been detected by both systems. The FM-CW data was obtained at microwave frequencies 8-12 GHz, while the ANA data was obtained at microwave frequencies $0.24-2.0 \mathrm{GHz}$. The total depth of the snow pack was $390 \mathrm{~cm}$.

The major part of the investigations during the $1977-78$ and $1978-79$ snow seasons was done in cooperation with the USDA Rocky Mountain Forest and Range Experiment Station at its field site on Berthoud Pass, Colorado. Additional investigations to verify snow-pack water equivalence were made at Loveland Pass, Colorado; Fraser, Colorado; and the Central Sierra Snow Laboratories, Soda Springs, California.

At the Berthoud Pass site, transmitting and receiving antennas were buried in a waterproof plastic enclosure beneath the ground prior to the $1977-78$ snow season. The undisturbed snow-pack which built up on top of the antennas was then monitored for several months. A

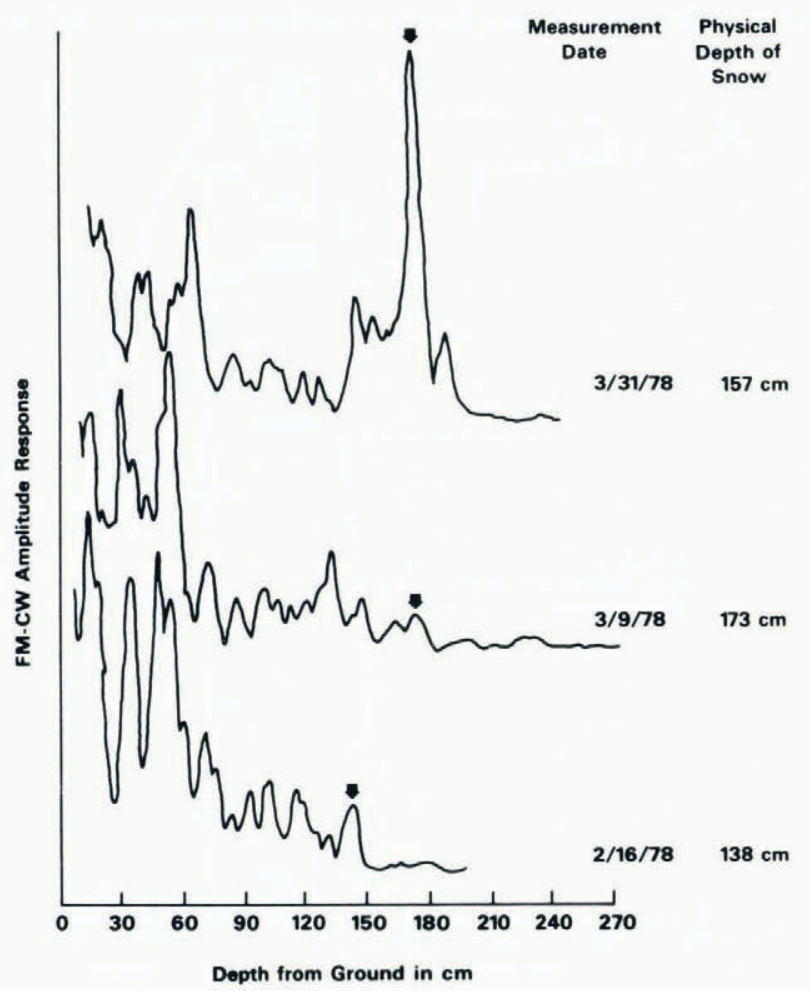

Fig. 5. Plot of FM-CW amplitude response as a function of depth for the period 16 February 1978 to 31 March 1978. 


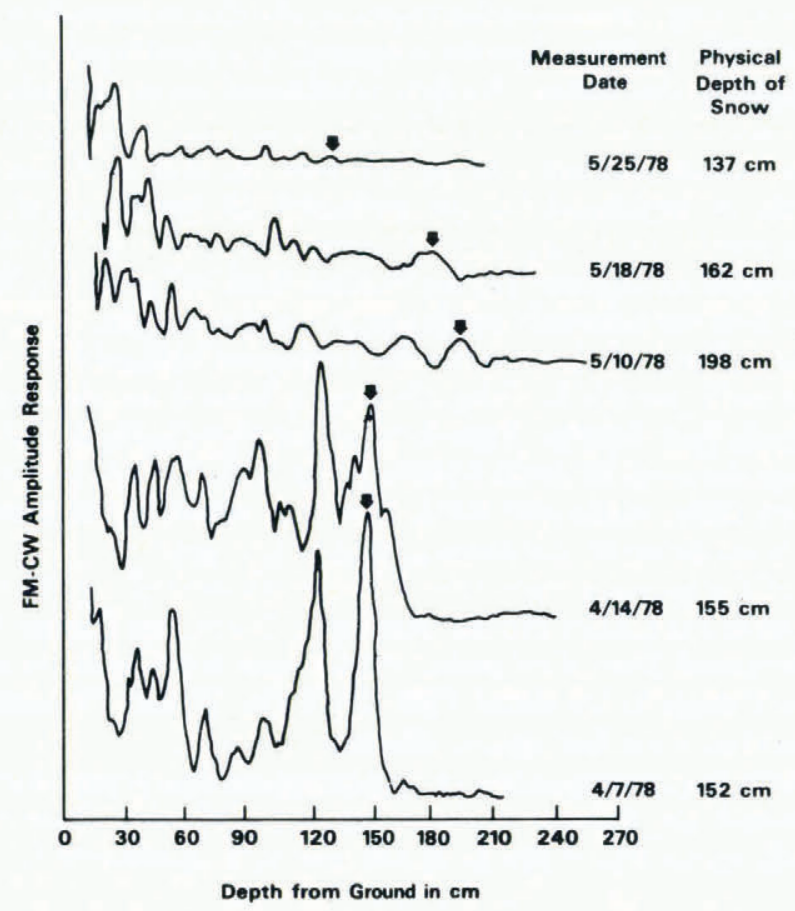

Fig. 6. Plot of FM-CW amplitude response as a function of depth for the period 7 April 1978 to 25 May 1978.

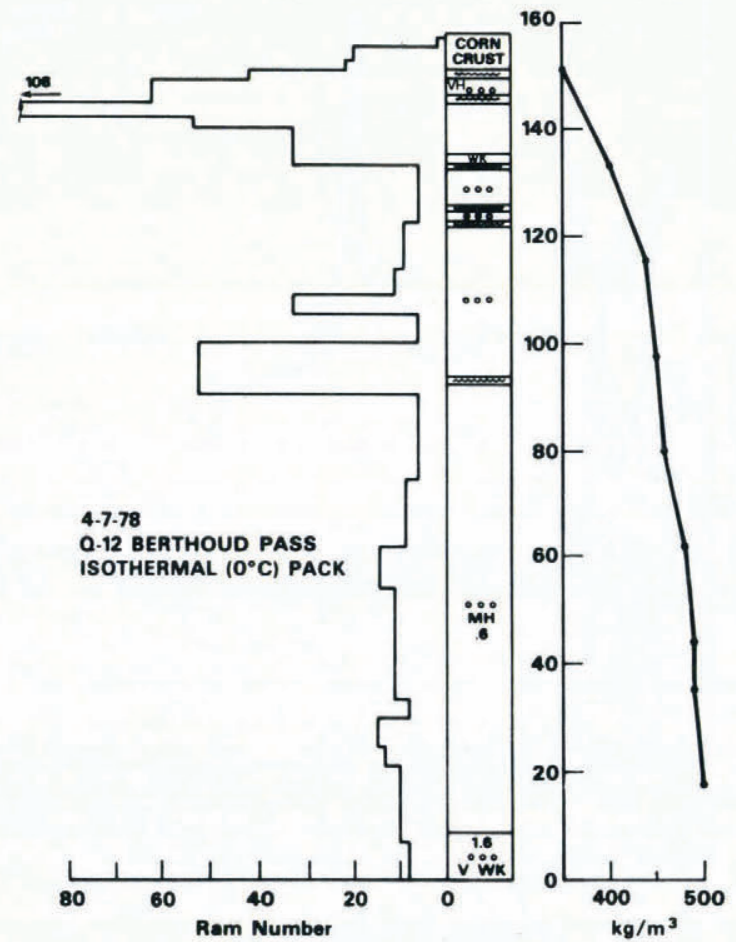

Fig. 7. Physical analysis of snow-pack, Berthoud Pass, 7 April 1978 isothermal $\left(0^{\circ} \mathrm{C}\right)$ snow-pack conditions. 
composite of specific microwave responses of amplitude versus depth of snow-pack from I 6 February 1978 , to 25 May 1978, are shown in Figures 5 and 6 . The arrows in Figures 5 and 6 indicate reflection from the surface of the snow-pack. The date and physical depth of snow-pack are tabulated in the right-hand columns. The amplitude variations as a function of depth indicate stratigraphic layering, which has been verified by physical analysis of pit data taken approximately two meters from the buried antennas. Figure 7 is one such plot of the snow-pack stratigraphy and resistance profile measurements for 7 April i978. These data should be compared with the bottom trace of Figure 6 .

The large amplitude responses in the upper layers of the pack for the top trace of Figure 5 and the two lower traces of Figure 6 represent ice layers formed by surface melt-freeze conditions. The pack progressed from temperature gradient to isothermal $\left(0^{\circ} \mathrm{C}\right)$ with the isothermal condition starting around 5 April 1978. There is an apparent loss of stratigraphy in the three upper traces of Figure 6, caused presumably by the percolation of free water through the snow-pack.

Measurements of snow-pack water equivalence were made by comparing a known volume of snow with the volume of water produced by melting the snow. We observed a correlation between the snow-pack water equivalence and the frequency range $\Delta f$ swept by the FM-CW system between the top and bottom of the snow-pack (Figs 5 and 6). To explain this result, we assume a two-component dielectric model of ice and air for the snow-pack (Kuroiwa, I962). This assumption was verified by null measurements of free water, using a freezing calorimeter technique (Jones, I979). A three-component model (ice, air, water) would be necessary if free water were present in the snow-pack. We can relate the frequency range $\Delta f$, to the snow-pack water equivalence in the following way. The snow-pack depth is given by (Ellerbruch and Belsher, 1978).

$$
\Delta f=K \sqrt{ } \epsilon_{\mathrm{s}}, d_{\mathrm{s}}
$$

where $K=2\left(f_{2}-f_{\mathrm{I}}\right) f_{n} / c$ is a radar system parameter and $f_{2}-f_{\mathrm{I}}$ the maximum sweep range of the FM-CW system, $f_{n}$ the number of sweeps per unit time, $c$ the speed of light, $d_{\mathrm{s}}$ the physical depth of the snow-pack, and $\epsilon_{\mathrm{s}}$ the dielectric constant of snow relative to air.

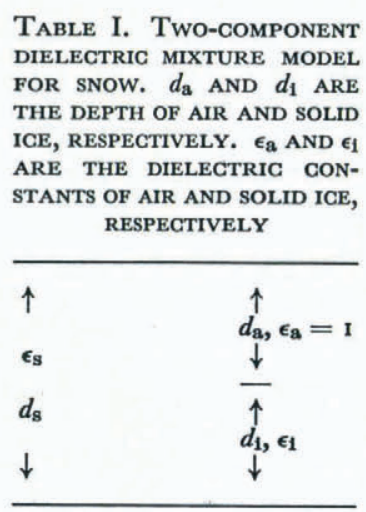

The term $d_{\mathrm{s}} \sqrt{ } \epsilon_{\mathrm{s}}$ is often referred to as the electrical path length of the medium, in this case, snow. In the two-component model, $d_{\mathrm{s}}=d_{\mathrm{i}}+d_{\mathrm{a}}$ where $d_{\mathrm{i}}$ and $d_{\mathrm{a}}$ are the depth of solid ice and air, respectively. Also, $d_{\mathrm{s}} \sqrt{ } \epsilon_{\mathrm{s}}=d_{\mathrm{i}} \sqrt{ } \epsilon_{\mathrm{i}}+d_{\mathrm{a}} \sqrt{ } \epsilon_{\mathrm{a}}=d_{\mathrm{i}} \sqrt{ } \epsilon_{\mathrm{i}}+d_{\mathrm{a}}$, where $\epsilon_{\mathrm{i}}$ and $\epsilon_{\mathrm{a}}$ are the relative dielectric constant of ice and air with respect to air, respectively, and $\epsilon_{\mathrm{a}}=\mathrm{I}$.

$$
\begin{aligned}
\Delta f & =K\left(d_{\mathrm{i}} \sqrt{ } \epsilon_{\mathrm{i}}+d_{\mathrm{a}}\right) \\
& =K\left(d_{\mathrm{i}} \sqrt{ } \epsilon_{\mathrm{i}}+d_{\mathrm{s}}-d_{\mathrm{i}}\right)
\end{aligned}
$$


and

$$
d_{\mathrm{i}}=\frac{\Delta f / K-d_{\mathrm{s}}}{\sqrt{ } \epsilon_{\mathrm{i}}-\mathrm{I}} .
$$

Because our snow-pack water-equivalence measurements are volumetric, the depth $d_{\mathrm{i}}$ of solid ice can be equated to depth $d_{\mathrm{w}}$ of water with an error of about $2 \%$. Therefore,

$$
d_{\mathrm{i}}=d_{\mathrm{w}}=\frac{\Delta f / K-d_{\mathrm{s}}}{\sqrt{ } \epsilon_{\mathrm{i}}-\mathrm{I}},
$$

where $\Delta f$ and $d_{\mathrm{s}}$ are measured. For these measurements, $f_{2}-f_{1}=4 \mathrm{GHz}$ and $f_{n}=100 \mathrm{~Hz}$ so that $K=2.67 \times \mathrm{IO}^{3}$. A graph of the measured versus the calculated snow-pack water equivalence is shown in Figure 8. The error between the measured and calculated water equivalence is $\pm 5 \%$. For an alpine snow-pack, we have observed that the average dielectric constant of snow ranges from $1.3-1.4$.

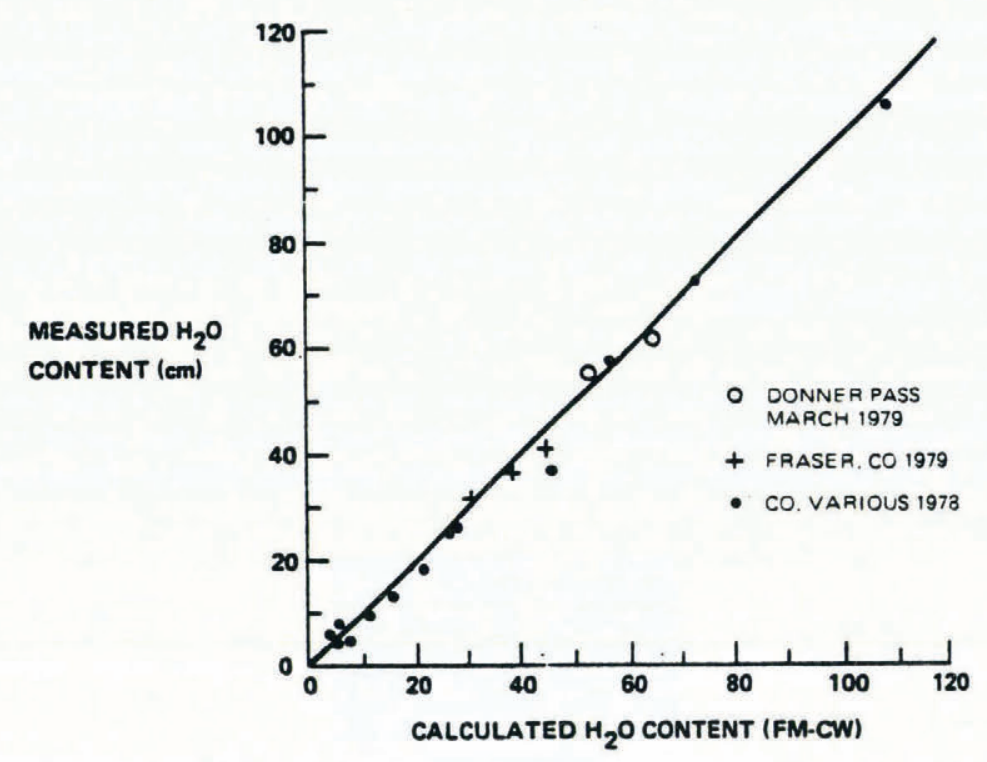

Fig. 8. Graph of measured water equivalence versus calculated water equivalence from FM-CW response.

\section{Conclusions}

We have observed changes in the snow-pack stratigraphy over several snow seasons. We have measured the snow-pack water equivalence with an accuracy of $\pm 5 \%$, using an FM-CW microwave system (Fig. 8). This implies that the same system can be used to measure snowpack loading (change in electrical depth) on an avalanche slope. There is evidence that the top of the depth-hoar layer exhibits a strong reflection (Fig. I) which can be monitored during the snow season. There is also evidence that while the physical depth of the pack diminishes in the latter part of the season, the water equivalence remains relatively constant (densification). Finally there is evidence that the ripeness of the snow-pack could be assessed by observing the diminution of stratigraphic layers in the late-season snow-pack (Fig. 6). These observations will be the subject of further study to relate them to avalanche modeling. 


\section{Acknowledgements}

It is a pleasure to acknowledge the cooperation and encouragement of several members of the U.S. Forest Service Rocky Mountain Forest and Range Experiment Station including M. Martinelli, D. Bachman, and E. Hennion. Facilities at the Central Sierra Snow Laboratories were arranged by Dr James Smith of the U.S. Forest Service and Dr William Linlor of National Aeronautics and Space Administration.

\section{REFERENCES}

Ambach, W., and Denoth, A. 1972. Frequenzgang und Relaxationszeiten der Dielektrizitätskonstante von Schneeproben nach dem Modell von Cole-Cole. Acta Physica Austriaca, Bd. 35, Ht. 3, p. $249-6$ r.

Cumming, W. A. 1952. The dielectric properties of ice and snow at 3.2 centimeters. Journal of Applied Physics, Vol. 23, No. 7, p. 768-73.

Ellerbruch, D. A., and Belsher, D. R. 1978. Electromagnetic techniques of measuring coal thickness. IEEE Transactions of Geoscience Electronics, Vol. GE-16, No. 2, p. 127-28.

Ellerbruch, D. A., and others. 1977. Microwave characteristics of snow, by D. A. Ellerbruch, W. E. Little, H. S. Boyne, and D. D. Bachman. Proceedings of the Western Snow Conference, 45th annual meeting, p. 68-74.

Evans, S. ${ }^{2} 965$. Dielectric properties of ice and snow-a review. Journal of Glaciology, Vol. 5, No. 42, p. 773-92.

[International Hydrological Decade.] 1970. Seasonal snow cover: a guide for measurement compilation and assemblage of data. Paris, UNESCO/IASH/WMO. (Technical Papers in Hydrology, 2.)

Jones, R. N. 1979. A comparison of centrifuge and freezing calorimeter measurements for measuring free water in snow. U.S. National Bureau of Standards. Internal Report, 79-1604.

Kuroiwa, D. I962. Electrical properties of snow. (In Bader, H., and Kuroiwa, D. The physics and mechanics of snow as a material. U.S. Cold Regions Research and Engineering Laboratory. Cold regions science and engineering . Hanover, N.H., Pt. II, Sect. B, p. 63-79.)

Linlor, W. I., and Jiracek, G. R. 1975. Electromagnetic reflection from multi-layered snow models. Fournal of Glaciology, Vol. 14, No. 72, p. $501-15$.

Linlor, W. I., and Smith, J. L. I974. Electronic measurements of snow sample wetness. (In Santeford, H. S., and Smith, J. L., comp. Advanced concepts and techniques in the study of snow and ice resources. Washington, D.C., National Academy of Sciences, p. 720-28.)

Linlor, W. I., and others. 1974. Microwave profiling of snowpack free-water content, [by] W. I. Linlor, M. F. Meier, J. L. Smith. (In Santeford, H. S., and Smith, J. L., comp. Advanced concepts and techniques in the study of snow and ice resources. Washington, D.C., National Academy of Sciences, p. 729-36.)

Vickers, R. S., and Rose, G. C. [1973.] High resolution measurements of snowpack stratigraphy using a short pulse radar. Proceedings of the eighth International Symposium on Remote Sensing of Environment, 1972, Vol. I, p. $26 \mathrm{I}-77$. 